\title{
Erratum
}

\section{Cognition at Each Stage of Lewy Body Disease with Co-occurring Alzheimer's Disease Pathology}

Pre-press 18 May 2021

Sephira G. Ryman, Maya Yutsis, Lu Tian, Victor W. Henderson, Thomas J. Montine, David P. Salmon, Douglas Galasko \& Kathleen L. Poston

[Journal of Alzheimer's Disease, 80(3) 2021, 1243-1256, DOI 10.3233/JAD-201187]

https://content.iospress.com/articles/journal-of-alzheimers-disease/jad201187

On page 1254, in the Acknowledgements section the following funding statement should be added:

"This study has been funded by the NATIONAL INSTITUTE OF GENERAL MEDICAL SCIENCES, with the award number; P30GM122734" 